\title{
The Risk Factors for Lumbar Disc Herniation in Mosul City
}

Ismail Hamad Alhaso*

\section{ABSTRACT}

Back ground and objectives: Lumbar disc herniation is one of the most important causes of lower back pain and is also one of the most important problems in orthopedic surgery in adults. The study aims to assessment the risk factors for lumbar disc herniation in the city of Mosul. Material and methods: - A retrospective study (a case control study) was conducted for a sample of adults consisting of (540) samples as all, divided into two groups of both sex (266) case and 274control, aged between 20 years and 70 years old and above. This study was carried out in the following hospitals: Al-Gomhouri Educational Hospital, Al-Salam General Hospital, and Ibn Sina Medical Center in Mosul. It was conducted for a period of three months from the first of January 2014 till the first of April 2014. The validity of the content was determined by presenting expert questionnaire forms consisting of (17) experts. The data were analyzed by applying the descriptive analysis, which included (frequency distribution, percentage) and deductive statistical analysis, which included patients and the control sample. The internal stability of the questionnaire was applying the Cronbach alpha correlation coefficient .

Results:- A number of factors were found to be significantly more effective in patients with lumbar disc herniation: gender, age, Residency, family history, increased working hours, back pain during work, working with big effort, psychosocial impact, washing the clothes both way, washing the dishes on the ground increasing the number of children, not doing sports weekly,. eating in sitting position, carrying heavy objects more than 15 kilos, sitting for long periods. Conclusion: LDH is more common in male than female group in a ratio of 1.74:1.

The age group most affected with LDH is $40-49$ years. LDH is more common in urban areas. BMI has direct effect on LDH especially persons who are with overweight. Married and primary persons have more groups affected with LDH. Family history plays a great role in existing the LDH $(63.2 \%)$. and the comorbidity diseases (DM.HT) also contributed to the LDH. Employee persons, Average of time work 710 hrs., Satisfaction of time work some of them, Addition work out org. work, Rest time during the work some of them, suffering Back pain during work, need speed during work and working with big effort have high significant in role the study whereas enough time to complete the work not significant .

Recommendation: the study recommended the establishment of educational programs for the community through all the media and the inclusion of the subject of disease to nursing students and health institutions aimed to reduce the disease and the study recommended also to reduce weight, doing regular exercises and improve physical activities.

Keywords: Assessment, Risk factors, lumber, Disc herniation, Mosul city.

\section{INTRODUCTION}

A herniated disk, also called prolapsed, ruptured or slipped disk is a protrusion of the disc beyond its natural borders. The most common symptom of the lumbar disc herniation is the low back pain which is radiating into one leg (Boos and Aebi, 2008). Radiculopathy is caused by compression or irritation of the nerves with resultant pain, weakness, and/or sensor impairment in the affected nerve root, may be from direct trauma or from chemical irritation to the affected nerve root (Kennedy et. al., 2011). Lumbar disc herniation (LDH), where the most common site is toward the bottom of the spine at L4-L5 or L5-S1 (95\%), makes up the vast majority of spinal disc herniation cases. (Postacchini and Postacchini, 2011) LDH occurs when the nucleus in the center of the disc pushes out of its normal space .
The nucleus presses against the annulus, causing the disc to bulge outward. With further progress, the nucleus herniates completely through the annulus and squeezes out of the disc, placing pressure on the spinal canal or nerve roots. (Strange et al., 2010) In addition, the nucleus releases chemicals that can irritate the surrounding nerves causing inflammation and pain (Guterl et al., 2013; Hou, et al; 2003).

General symptoms of LDH include one, or a combination, of the following: typical sciatica symptoms such as numbness, weakness, and/or tingling in the specific region in leg and/or foot, and/or foot pain, lower back pain, and/or pain in the buttock; and loss of bladder or bowel control, indicating a serious medical condition called cauda equina syndrome (Daoyoue et al., 2013). Normally, daily activities cause the nucleus to press against the

* MSc Candidate/ Salahudeen Health Directorate

** Professor/College of Nursing/University of Mosul . 
annulus fibrosus. This pressure is not sufficient to cause disease. However, the annulus tends to crack and tear with age and degeneration. With weakness in the annulus, the nucleus may begin to herniate (squeeze) through the damaged annulus. The pressure bulges the annulus outward in the beginning. Eventually, the nucleus herniates completely through the outer ring of the disc. Therefore, it seems that aging is a risk factor and a contributor to the incidence of LDH, which increases with age. (Ma et al., 2013; Zigouris et al., 2011; Dammers and Koehler ,2002).

Lower back pain (LBP) is the second most common neurological ailment in the United States after the headache (NINDS, 2008). According to the Center of Disease Control (CDC) back problems is the second most common cause of disabilities $(16.5 \%$ of all disabilities) after the arthritis and rheumatism (17.5\% of all disabilities) in the USA (CDC, 2001).

The intervertebral disc connects the vertebrae to a functional unit. Its role is mechanical, acting as an absorber of load forces and as a joint allowing motion in all planes. The outer part, annulus fibrosus consists of lamellae rich collagen which is structurally and functionally different from the inner part nucleus pulposus which is gelatinous in texture and rich in proteoglycan. The latter provides the disc with its osmotic properties and its ability to resist compressive loads (Urban, 2000). A disc herniation was first described by Mixter and Barr as a rupture of the annulus fibrosus with leakage of the nucleus pulposus into the intervertebral space. Among several

Factors which can contribute to disc herniation, degenerative changes are the most common (Beattie, 2008). Disc degeneration is regarded as a weakening, complex multifactorial disease determined by the interplay between genes and the environment (Chan et al., 2006). The morbidity curve for disc herniation, however, does not follow the corresponding curve for degeneration. While disc degeneration proceeds with time and is mostly pronounced in the aging spine, Symptoms of lumbar disc herniation are the most common in the middle age (Beattie, 2008).

Genetic disposition, mechanical compression, e.g. heavy torque strain (Beattie, 2008; Beattie et al., 2004) and vigorous physical activity, low frequency vibrations, trauma ,obesity and psychosocial stress are all factors which have been referred to as promoters of disc degeneration and subsequent herniation (jansson,2005; Ostelo,2005) Research from the last decade has resulted in a shift from heavy physical loading to genetic disposition being considered the main risk factor in the etiology of disc degeneration (Beattie et al., 2004; Rhee, 2006). Still, the degenerative progression may be influenced by environmental factors (Beattie, 2008 ) smoking and exposure to vehicular vibration dominated much of the last century( Borenstein,2001). The contribution of other factors such as height, weight and genetics is less certain (Frymoyer, 1992). In recent years, however, a dramatic advance has been made in understanding of genetic influences on the risk for disc degeneration, Genetic factors, in particular, may be largely responsible for the degeneration as well as herniation of intervertebral disc (Battié, 2007) prevalence of lost-work day back pain among the working population is estimated to be $4.6 \% 10$. The herniated disc is thought to account for $5 \%$ of all case (Reyaz, 2003). Most of the research related to spine surgery is focused on the methods and techniques of diagnostics, therapy, and rehabilitation, but hardly anything has been published on height of the patients as a risk factor. A screening method for increased risk could be developed for identifying risk factors very early and thus avoiding the need for spine surgery through counseling within the primary health care and lifestyle modification (Alashaw, 2011). The objectives treatment is to relive pain, slow disease progression, and increase the patient's functional ability to regain his/her life activity .

Complete bed rest, previously standard in treatment of back pain ,is recommended 2 days or less (Hickey,2009).because muscle spasm is prominent during the acute phase of disease drugs of muscle relaxants may use .NSAIDs and systemic corticosteroids may be administered as prescribed to counter the inflammation that usually occurs in the supporting tissue and the affected nerve roots . physiotherapy as moist heat and message help relax muscles. .

Strategies for increasing the patients functional ability include weight reduction ,physical therapy and biofeedback ,exercises ,prescribed by physical therapists can be help strength back muscles and decrease pain (Hicky, 2009).

\section{MATERIALS AND METHOD}

A retrospective case-control design approach was carried out in order to achieve the 
objectives of the present study. Was conducted for a period of three months from the first of January 2014 till the first of April 2014in orthopedic and rheumatology consultations in Mosul teaching hospitals (Ibn-Sina,Al Jumhori , AL-Salam teaching hospitals). A non-probability (purposive) sample was selected. . Total of (266) hospitalized patients, diagnosed with LDH by CT and/or MRI were selected as cases. A total of (274) people from communities and hospitals, without history of lumbar disc herniation, were selected as controls. All patients and controls were investigated for demographical data, medical history, occupational characters, working, psychosocial factors, and gynecological history for females, life style, life activity, and major life events. A special questionnaire was constructed, and interview method was used to gather the data concerning the subject of the study. The questionnaire was designed by the researcher making use of literature review, opinion of supervisor, opinion of experts and pilot study. The validity of the questionnaire was determined by exposing it to17 specialized experts in different fields of sciences, whereas, their comments was followed in the final draft of the tool, Data were prepared, organized and entered into a computer file; Statistical Package for the Social Science (SPSS, version 15) was used for data analysis.

\section{RESULTS}

Table (1): sample Frequency distribution and chi-square of study according to their demographic characteristics (case and control) .

\begin{tabular}{|c|c|c|c|c|c|c|c|}
\hline \multirow{2}{*}{\multicolumn{2}{|c|}{ Variables. }} & \multicolumn{2}{|c|}{$\begin{array}{c}\text { (case) } \\
266\end{array}$} & \multicolumn{2}{|c|}{ (control) 274} & \multirow[t]{2}{*}{$\mathbf{X}^{2}$} & \multirow[t]{2}{*}{ Sig. } \\
\hline & & \multirow{3}{*}{$\begin{array}{c}\text { No. } \\
169 \\
97\end{array}$} & \multirow{3}{*}{$\begin{array}{c}\mathbf{\%} \\
63.5 \% \\
36.5 \%\end{array}$} & \multirow{2}{*}{$\begin{array}{l}\text { No. } \\
177 \\
\end{array}$} & \multirow{3}{*}{$\begin{array}{c}\mathbf{\%} \\
64.6 \% \\
35.4 \%\end{array}$} & & \\
\hline \multirow{2}{*}{ Gender } & Male & & & & & \multirow{2}{*}{0.066} & \multirow{2}{*}{0.797} \\
\hline & Female & & & 97 & & & \\
\hline \multicolumn{8}{|c|}{ Sig. : 0.05} \\
\hline \multirow{6}{*}{ Age } & $20-29$ & 47 & $17.7 \%$ & 48 & $17.5 \%$ & \multirow{6}{*}{0.250} & \multirow{6}{*}{0.998} \\
\hline & $39-30$ & 49 & $18.4 \%$ & 48 & $17.5 \%$ & & \\
\hline & $49-40$ & 88 & $33.1 \%$ & 96 & $35.0 \%$ & & \\
\hline & $59-50$ & 54 & $20.3 \%$ & 54 & $19.7 \%$ & & \\
\hline & $69-60$ & 22 & $8.3 \%$ & 22 & $8.0 \%$ & & \\
\hline & more-70 & 6 & $2.3 \%$ & 6 & $2.2 \%$ & & \\
\hline \multicolumn{8}{|c|}{ Sig. : 0.05} \\
\hline \multirow{2}{*}{ Residency. } & rural & 85 & $32.0 \%$ & 72 & $26.3 \%$ & \multirow{2}{*}{2.110} & \multirow{2}{*}{0.146} \\
\hline & urban & 181 & $68.0 \%$ & 202 & $73.7 \%$ & & \\
\hline \multicolumn{8}{|c|}{ Sig. : 0.05} \\
\hline \multirow{5}{*}{ BMI } & Under weight & 1 & $0.4 \%$ & 1 & $0.4 \%$ & \multirow{5}{*}{51.105} & \multirow{5}{*}{0.000} \\
\hline & Normal weight & 25 & $9.4 \%$ & 29 & $10.6 \%$ & & \\
\hline & Over weight & 185 & $69.5 \%$ & 210 & $76.6 \%$ & & \\
\hline & obesity & 14 & $5.3 \%$ & 34 & $12.4 \%$ & & \\
\hline & Morbid obesity & 41 & $15.4 \%$ & 0 & $0.0 \%$ & & \\
\hline \multicolumn{8}{|c|}{ Sig. : 0.05} \\
\hline \multirow{4}{*}{ Marital status } & single & 26 & $9.8 \%$ & 18 & $6.6 \%$ & \multirow{4}{*}{3.089} & \multirow{4}{*}{0.378} \\
\hline & married & 227 & $85.3 \%$ & 237 & $86.5 \%$ & & \\
\hline & divorced & 6 & $2.3 \%$ & 11 & $4.0 \%$ & & \\
\hline & widower & 7 & $2.6 \%$ & 8 & $2.9 \%$ & & \\
\hline \multicolumn{8}{|c|}{ Sig. : 0.05} \\
\hline \multirow{5}{*}{$\begin{array}{l}\text { Level of } \\
\text { education }\end{array}$} & illiterate & 37 & $13.9 \%$ & 41 & $15.0 \%$ & & \\
\hline & primary & 101 & $38.0 \%$ & 116 & $42.3 \%$ & & \\
\hline & secondary & 68 & $25.6 \%$ & 65 & $23.7 \%$ & 3.775 & 0.437 \\
\hline & institute & 38 & $14.3 \%$ & 26 & $9.5 \%$ & & \\
\hline & Bachelor and above & 22 & $8.3 \%$ & 26 & $9.5 \%$ & & \\
\hline
\end{tabular}


Table (2): sample Frequency distribution and chi-square of study according to their medical history (case and control).

\begin{tabular}{|c|c|c|c|c|c|c|c|}
\hline \multirow{2}{*}{\multicolumn{2}{|c|}{ Var. }} & \multicolumn{2}{|c|}{$\begin{array}{c}\text { (case) } \\
266\end{array}$} & \multicolumn{2}{|c|}{$\begin{array}{c}\text { (control) } \\
274\end{array}$} & \multirow[t]{2}{*}{$\mathbf{X}^{2}$} & \multirow[t]{2}{*}{ Sig. } \\
\hline & & No. & $\%$ & No. & $\%$ & & \\
\hline \multirow{2}{*}{ LDH history } & yes & 168 & $63.2 \%$ & 68 & $24.8 \%$ & \multirow{2}{*}{80.640} & \multirow{2}{*}{0.000} \\
\hline & No & 98 & $36.8 \%$ & 206 & $75.2 \%$ & & \\
\hline \multirow{2}{*}{ Pain for 7 days } & yes & 41 & $15.4 \%$ & 9 & $3.3 \%$ & \multirow{2}{*}{23.632} & \multirow{2}{*}{0.000} \\
\hline & No & 225 & $84.6 \%$ & 265 & $96.7 \%$ & & \\
\hline \multirow{2}{*}{ Chronic dis. } & yes & 59 & $22.2 \%$ & 38 & $13.9 \%$ & \multirow{2}{*}{6.328} & \multirow{2}{*}{0.012} \\
\hline & No & 207 & $77.8 \%$ & 236 & $86.1 \%$ & & \\
\hline $\mathrm{DF}=1$ & Sig. & & & & & & \\
\hline \multirow{3}{*}{$\begin{array}{l}\text { If the answer was } \\
\text { yes }\end{array}$} & $\mathrm{DM}$ & 21 & $35.6 \%$ & 16 & $42.1 \%$ & \multirow{3}{*}{2.358} & \multirow{3}{*}{0.308} \\
\hline & $\mathrm{HT}$ & 21 & $35.6 \%$ & 8 & $21.1 \%$ & & \\
\hline & others & 17 & $28.8 \%$ & 14 & $36.8 \%$ & & \\
\hline
\end{tabular}

Table (3): sample Frequency distribution and chi-square of study according to their work (case and control).

\begin{tabular}{|c|c|c|c|c|c|c|c|}
\hline \multirow{2}{*}{\multicolumn{2}{|c|}{ Var. }} & \multicolumn{2}{|c|}{$\begin{array}{ll}\text { (case) } 266 \\
\end{array}$} & \multicolumn{2}{|c|}{ (control) 274} & \multirow{2}{*}{$\mathbf{X}^{2}$} & \multirow{2}{*}{ Sig. } \\
\hline & & \multirow{2}{*}{$\begin{array}{l}\text { No. } \\
148 \\
\end{array}$} & \multirow{2}{*}{$\begin{array}{c}\% \\
55.6 \% \\
\end{array}$} & \multirow{2}{*}{$\begin{array}{l}\text { No . } \\
165 \\
\end{array}$} & \multirow{2}{*}{$\frac{\%}{60.2 \%}$} & & \\
\hline \multirow{3}{*}{ Type of work } & unemployed & & & & & \multirow{3}{*}{2.350} & \multirow{3}{*}{0.309} \\
\hline & $\begin{array}{l}\text { Government } \\
\text { employee }\end{array}$ & 103 & $38.7 \%$ & 100 & $36.5 \%$ & & \\
\hline & Native company & 15 & $5.6 \%$ & 9 & $3.3 \%$ & & \\
\hline \multirow{3}{*}{ Nature of work } & Official & 27 & $10.2 \%$ & 46 & $16.8 \%$ & \multirow{3}{*}{5.716} & \multirow{3}{*}{0.057} \\
\hline & physical & 198 & $74.4 \%$ & 195 & $71.2 \%$ & & \\
\hline & Both & 41 & $15.4 \%$ & 33 & $12.0 \%$ & & \\
\hline \multirow{3}{*}{ Average of time work } & $3-6$ & 56 & $21.1 \%$ & 95 & $34.7 \%$ & \multirow{3}{*}{17.261} & \multirow{3}{*}{0.000} \\
\hline & $7-10$ & 154 & $57.9 \%$ & 148 & $54.0 \%$ & & \\
\hline & 11-more & 56 & $21.1 \%$ & 31 & $11.3 \%$ & & \\
\hline \multirow{3}{*}{ Satisfaction of time work } & yes & 95 & $35.7 \%$ & 105 & $38.3 \%$ & \multirow{3}{*}{24.290} & \multirow{3}{*}{0.000} \\
\hline & No & 68 & $25.6 \%$ & 27 & $9.9 \%$ & & \\
\hline & Some times & 103 & $38.7 \%$ & 142 & $51.8 \%$ & & \\
\hline \multirow{3}{*}{$\begin{array}{l}\text { Addition work out org. } \\
\text { work }\end{array}$} & Yes & 83 & $31.2 \%$ & 32 & $11.7 \%$ & \multirow{3}{*}{41.304} & \multirow{3}{*}{0.000} \\
\hline & No & 125 & $47.0 \%$ & 127 & $46.4 \%$ & & \\
\hline & Sometimes & 58 & $21.8 \%$ & 115 & $42.0 \%$ & & \\
\hline \multirow{3}{*}{ Rest time } & Yes & 99 & $37.2 \%$ & 173 & $63.1 \%$ & \multirow{3}{*}{38.428} & \multirow{3}{*}{0.000} \\
\hline & No & 45 & $16.9 \%$ & 19 & $6.9 \%$ & & \\
\hline & Sometimes & 122 & $45.9 \%$ & 82 & $29.9 \%$ & & \\
\hline & Yes & 119 & $44.7 \%$ & 10 & $3.6 \%$ & \multirow{3}{*}{125.324} & \multirow{3}{*}{0.000} \\
\hline Back pain in work & No & 60 & $22.6 \%$ & 109 & $39.8 \%$ & & \\
\hline & Sometimes & 87 & $32.7 \%$ & 155 & $56.6 \%$ & & \\
\hline & Yes & 46 & $17.3 \%$ & 3 & $1.1 \%$ & & \\
\hline Work tempo & No & 80 & $30.1 \%$ & 169 & $61.7 \%$ & 75.411 & 0.000 \\
\hline & Sometimes & 140 & $52.6 \%$ & 102 & $37.2 \%$ & & \\
\hline & Yes & 43 & $16.2 \%$ & 10 & $3.6 \%$ & & \\
\hline Work with big effort & No & 94 & $35.3 \%$ & 185 & $67.5 \%$ & 62.143 & 0.000 \\
\hline & Sometimes & 129 & $48.5 \%$ & 79 & $28.8 \%$ & & \\
\hline & Yes & 112 & $42.1 \%$ & 128 & $46.7 \%$ & & \\
\hline Enough time to finish work & No & 53 & $19.9 \%$ & 45 & $16.4 \%$ & 1.602 & 0.449 \\
\hline & Sometimes & 101 & $38.0 \%$ & 101 & $36.9 \%$ & & \\
\hline & $\mathrm{DF}=2$ & & Sig. : & & & & \\
\hline
\end{tabular}


Table (4): sample Frequency distribution and chi-square of study according to their female questions (before diagnosis) (case and control)

\begin{tabular}{|c|c|c|c|c|c|c|c|}
\hline \multirow{2}{*}{ Var. } & & \multicolumn{2}{|c|}{ Female (case) } & \multicolumn{2}{|c|}{$\overline{\text { Female (control) }}$} & \multirow{2}{*}{$\mathbf{X}^{2}$} & \multirow{2}{*}{ Sig. } \\
\hline & & No. & $\%$ & No. & $\%$ & & \\
\hline \multirow{3}{*}{$\begin{array}{l}\text { Washing of } \\
\text { clothes }\end{array}$} & $\overline{\text { Manual }}$ & 20 & $20.6 \%$ & 7 & $7.2 \%$ & \multirow{3}{*}{10.610} & \multirow{3}{*}{0.005} \\
\hline & Washing machine & 22 & $22.7 \%$ & 38 & $39.2 \%$ & & \\
\hline & Both & 55 & $56.7 \%$ & 52 & $53.6 \%$ & & \\
\hline \multirow{3}{*}{$\begin{array}{l}\text { Washing of } \\
\text { dishes }\end{array}$} & On the ground & 15 & $15.5 \%$ & 4 & $4.1 \%$ & \multirow{3}{*}{10.199} & \multirow{3}{*}{0.006} \\
\hline & On the stage & 63 & $64.9 \%$ & 81 & $83.5 \%$ & & \\
\hline & Both & 19 & $19.6 \%$ & 12 & $12.4 \%$ & & \\
\hline \multicolumn{8}{|c|}{$\begin{array}{ll}\mathrm{DF}=2 & \text { Sig. }: 0.05\end{array}$} \\
\hline \multirow{4}{*}{ No .of gravid } & $1-3$ & 18 & $18.6 \%$ & 32 & $33.0 \%$ & \multirow{4}{*}{10.310} & \multirow{4}{*}{0.016} \\
\hline & $4-6$ & 43 & $44.3 \%$ & 46 & $47.4 \%$ & & \\
\hline & 7 -and more & 28 & $28.9 \%$ & 17 & $17.5 \%$ & & \\
\hline & Not exist & 8 & $8.2 \%$ & 2 & $2.1 \%$ & & \\
\hline \multirow{4}{*}{ No. of N.V.D } & $1-3$ & 23 & $23.7 \%$ & 34 & $35.1 \%$ & \multirow{4}{*}{12.700} & \multirow{4}{*}{0.005} \\
\hline & $4-6$ & 43 & $44.3 \%$ & 52 & $53.6 \%$ & & \\
\hline & 7 -and more & 23 & $23.7 \%$ & 9 & $9.3 \%$ & & \\
\hline & Not exist & 8 & $8.2 \%$ & 2 & $2.1 \%$ & & \\
\hline \multirow{4}{*}{ No. Of childes } & $1-3$ & 18 & $18.6 \%$ & 36 & $37.1 \%$ & \multirow{4}{*}{17.108} & \multirow{4}{*}{0.001} \\
\hline & $4-6$ & 41 & $42.3 \%$ & 46 & $47.4 \%$ & & \\
\hline & 7-and more & 28 & $28.9 \%$ & 13 & $13.4 \%$ & & \\
\hline & Not exist & 10 & $10.3 \%$ & 2 & $2.1 \%$ & & \\
\hline \multirow{4}{*}{$\begin{array}{l}\text { No. } \\
\text { cesareans } \\
\text { Operations }\end{array}$} & Once & 18 & $18.6 \%$ & 29 & $29.9 \%$ & \multirow{4}{*}{7.132} & \multirow{4}{*}{0.248} \\
\hline & two & 7 & $7.2 \%$ & 4 & $4.1 \%$ & & \\
\hline & More than two & 5 & $5.2 \%$ & 6 & $6.2 \%$ & & \\
\hline & Not exist & 67 & $69.1 \%$ & 58 & $59.8 \%$ & & \\
\hline
\end{tabular}

\section{DISCUSSION}

(A) Characteristics of the sample:

Discussion of socio-demographic characteristics of the patientes (Table 1)

The lumbar disc herniation is common in males and constituted of $(63.5 \%)$ while in control group in males were $(64.6 \%)$. High percentage in age most patients at age between (40-49) and constitute (31.1\%) in cases and (35.0\%) for control group. With regard to residence $(68.0 \%)$ were living in urban areas for cases and $(73.7 \%)$ for control group, most of the cases were overweight (69.5\%) and (76.6\%) for control group have high sig only in table. most of the patients were married and constituted $(85.3 \%)$ for cases and $(86.5 \%)$ for control group , $(38.0 \%)$ of the sample were primary school (42.3\%) in control group.

\section{(B) Discussion of medical history.}

The highly significant association between case and control in presence of family history, Battie et al; (2009) they found extensive relation of family history to lumbar herniated discs is the best predictor of a future herniation. The medical literature has shown a hereditary tendency for disc degeneration, and disc degeneration is associated with an increased risk for a herniation. pain for 7days , chronic disease and LDH, (63.2)\% of cases had a family history of LDH compared to (24.8\%) of controls ,the pain for 7days were negative in studied group $(84.6 \%)$ while in control group were positive (96.7\%),chronic disease were negative in studied groups $(77.8 \%)$, while the $(86.1 \%)$ in control group .DM and HT as accomitant disease were equal highest percentage $(35.6 \%)$ but controls groups $(42.1 \%)$ for DM and $(21.1 \%)$ for HT ,the lowest percentage was for other diseases $(28.8 \%)$ for studied groups and $(36.8 \%)$ for control groups.

Discussion of part of work.

there is significant association between case -control in Type of work especially employee, Nature of work, Average of time work, Satisfaction of time work, Addition work out org. Work, Rest time, Back pain in work, Work tempo, Work with big effort, while there No significance association in Enough time to finish work at $\mathrm{P}$.value $(0.05) \%$. Several studies point to a relation between $\mathrm{LDH}$ and occupation. this present study agree with Andreas et al. (2009). Another study submitted 
by Seidler et al; (2009). Aimed to find Cumulative occupational lumbar load and lumbar disc disease--results of a German multicenter study was case control study. They found a positive dose-response relationship between cumulative occupational lumbar load and lumbar disc herniation as well as LDH among men and women.

Discussion part of females: This part is related to gynecological and home responsibility questions and shows high significance association between case and control in washing of clothes, washing of dishes, No .of gravid, No. of N.V.D, No. Of Childs 4-6 in number while in No. Of cesareans operations there's no significant association at $\mathrm{P}$. value (0.05).in the current study the females who are washing clothes both in manual and washing machine got a higher percentage $56.7 \%$ while women washing the dishes on the stage was more than the females washing on the ground. This may be because women spend more time on the stage to further work in the kitchen .Number of gravida 4-6 childes and N.V.D was respectively percentage $44.3 \%$ the women who have 4-6 children were withe LDH $42.3 \%$ while the women have no chance in operating the cesarean section was $69.1 \%$.

Discussion Part of major life events : Results of lumber herniated patients with major life events showed high significance between case and control in A sudden for event for relative was percentage $57.9 \%$ that may explain the losing or happing some sudden event to close relative may have a relationship with $\mathrm{LDH}$.but other groups there is not any relation with lumber disc herniation. In Iraq, according to United Nations Assistance Mission for Iraq (UNAMI) the number of total killers in Iraq resulting of war and military action 359,549 as known all of the persons have relatives (Haidary, 2016).

\section{CONCLUSION}

On the bases of the objectives of the current study and outcomes of data analysis, the following have been concluded: LDH is more common in male than female group in a ratio of 1.74:1.

The age group most affected with LDH is 40-49 years. LDH is more common in urban areas. BMI has direct effect on LDH especially persons who are with overweight. Married and primary persons have more groups affected with LDH. Family history plays a great role in existing the LDH (63.2\%). and the comorbidity diseases (DM.HT) also contributed to the LDH. Employee persons, Average of time work 7-10 hrs., Satisfaction of time work some of them, Addition work out org. work, Rest time during the work some of them, suffering Back pain during work, need speed during work and working with big effort have high significant in role the study whereas enough time to complete the work not significant .

\section{RECOMMENDATIONS}

Depending on the findings and conclusions of the study, the researcher recommends the followings:- Proceeding future researches may find a relationship between the risk factors and socio-demographical data, study prevalence of $\mathrm{LDH}$, effects of lifestyle and dietary interventions, incidence of cauda equina syndrome, and the effectiveness of combination therapies among men and women in Mosul city. Different media should be used for public education like primary health centers, and television, social media, meeting, to clarify the risk factors. Work shop for nursing training process in hospitals and nursing colleges about anatomy, explanation of risk factors, physical examination and interpretation of radiological findings, nursing management .An educational program regarding prevention of $\mathrm{LDH}$, avoid obesity ,reduce time of work, avoid additional time as possible, working with big effort, maintain a physically active lifestyle with adequate week sporting, reduce setting for long period, and other factors related to assessing of lumber disc herniation should be established in collaboration with Health Governorate, medical colleges, nursing colleges and the World Health Organization .

Verbalizing nursing role to provide nursing management and give advice to all persons who have LDH.

\section{REFERENCES.}

Alashaw, j. (2011). The impact of height, weight and body mass Index on the occurrence of herniated intervertebral lumbar disc. Tikrit Medical Journal. 17(1). P.p.133137

Andreas Seidler, Annekatrin Bergmann, Matthias Jäger, Rolf Ellegast,Dirk Ditchen, Gine Elsner, Joachim Grifka6, Johannes Haerting,Friedrich Hofmann, Oliver Linhardt, Alwin Luttmann, Martina Michaelis, Gabriela PetereitHaack, Barbara Schumann. (2009). Australian Institute of Health and Welfare. 
Battié MC, Videman T, Levalahti E, Gill K, Kaprio J. (2007). Heritability of low back pain and the role of disc degeneration. Pain. 131. P.p.272-280

Battie, MC.; Videman, T.; Parent E. (2004). Lumbar disc degeneration: epidemiology and genetic influences. Spine 29. P.p.2679-90

Beattie, PF. (2008). Current understanding of lumbar intervertebral disc degeneration: a review with emphasis upon etiology.

Chan, D.; Song, Y.; Sham, P.; Cheung, KM. (2006). Genetics of disc degeneration. Eur Spine J. 15(3). P.p.S317-25

Dammers, R.; Koehler, PJ. (2002). Lumbar disc herniation: level increases with age. Surg Neurol. 58(3-4). P.p. 209-212

Daoyou, Ma.;Yunbiao, Liang.; Daoming Wang; Zejiang Liu; Wei Zhang1 Tantan Ma; Liang Zhang; Xingjun Lu; Zhiyou Cai. (2013). Trend of the incidence of lumbar disc herniation: decreasing with aging in the elderly.dove press $j .8$. P.p.1047-1050.

From the Centers for Disease Control and Prevention. (1999). Prevalence of disabilities and associated health conditions among adults--United States. JAMA, 2001. 285(12). P.p. 1571-2

Frymoyer JW. Lumbar disk disease.(1992). epidemiology. Instr Course Lect.41. P.p. 217-223

Guterl, CC.; See, EY.; Blanquer, SB.; et al. (2013). Challenges and strategies in the repair of ruptured annulus fibrosus. Eur Cell Mater. 25. P.p.1-21

Hickey,j.v. (2009). The clinical practice of nurological \& Nurosurgicl Nursing. $\left(6^{\text {th }}\right.$ ed.).philadelphia:lippincott williams \& willkins.
Jansson K-Å On. (2005). lumbar spinal stenosis and disc herniation surgery. Doctoral Thesis. Department of surgical sciences, Karolinska Institutet Stockholm

Kennedy DJ et. al. (2011). The role of core stabilization in lumbosacral radiculopathy. 22(1). P.p.91-103

NINDS. (2008). "National institute of neurological disorders and stroke (ninds): Low back pain fact sheet," NIND brochure.

Postacchini F. (1999). Management of herniation of the lumbar disc. $J$ Bone Joint Surg Br. 81. P.p.567-76

Reyaz A T. (2003). Chronic Low Back Pain Comparative Analysis of Treatment Response to Drugs and Different Physical Modalities. JK-Practionar. 10 (3). P.p. $201-204$.

Seidler A, Bergmann A, Jäger M, Ellegast R, Ditchen D, Elsner G, Grifka J, Haerting J, Hofmann F, Linhardt O, Luttmann A, Michaelis M, Petereit-Haack G, Schumann B, Bolm-Audorff U.2009. Cumulative occupational lumbar load and lumbar disc disease--results of a German multi-center case-control study . BMC Musculoskelet Disord. 10:48. doi: 10.1186/1471-2474-10-48.

Strange DG, Fisher ST, Boughton PC, Kishen TJ, Diwan AD. (2010). Restoration of compressive loading properties of lumbar discs with a nucleus implant-a finite element analysis study. Spine $J$. 10(7). P.p.602-609

AL-Haidary, Z. (2016). July. Omar Ali executive producer. middle east news. Ruadaw channel internet recourse. 